\title{
Supine versus prone position in percutaneous
}

\section{nephrolithotomy: a systematic review and meta-analysis}

\section{[version 1; peer review: 2 approved, 1 approved with}

\section{reservations]}

\author{
Ponco Birowo (D)1, William Tendi(D1, Indah S. Widyahening (D2), Nur Rasyid (D)1, \\ Widi Atmoko (D)1
}

\footnotetext{
1Department Urology, Faculty of Medicine Universitas Indonesia / Cipto Mangunkusumo Hospital, Jakarta Pusat, DKI Jakarta, 10430, Indonesia

${ }^{2}$ Department of Community Medicine, Faculty of Medicine Universitas Indonesia, Jakarta Pusat, DKI Jakarta, 10430, Indonesia
}

\author{
V1 First published: 02 Apr 2020, 9:231 \\ https://doi.org/10.12688/f1000research.22940.1 \\ Second version: 24 Aug 2020, 9:231 \\ https://doi.org/10.12688/f1000research.22940.2 \\ Latest published: 15 Sep 2020, 9:231 \\ https://doi.org/10.12688/f1000research.22940.3
}

\section{Abstract}

Background: The decision for using supine or prone position in percutaneous nephrolithotomy (PCNL) is still debatable. The aim of this study is to compare the efficacy and safety profile of the supine and prone position when performing PCNL.

Methods: A systematic electronic search was performed using the database from MEDLINE, Cochrane library and Google Scholar from January 2009 to November 2019. The outcomes assessed were stone free rate, major complication rate, length of hospital stay and mean operation time.

Results: A total of 11 articles were included in qualitative and quantitative analysis. The efficacy of PCNL in supine position as determined by stone free rate is significantly lower than in prone position (OR: 0.74; 95\% CI: 0.66 - 0.83; $p<0.00001$ ), However, major complication rate is also lower in the supine group compared with the prone group (OR: $0.70 ; 95 \% \mathrm{CI}: 0.51-0.96 ; \mathrm{p}=0.03$ ). There is no statistically significant difference in the length of hospital stay and mean operation time between both groups.

Conclusion: Prone position leads to a higher stone free rate, but also a higher rate of major complication. Thus, the decision of using which position during PCNL should be based on the surgeon's experience and clinical aspects of the patients.

\section{Open Peer Review

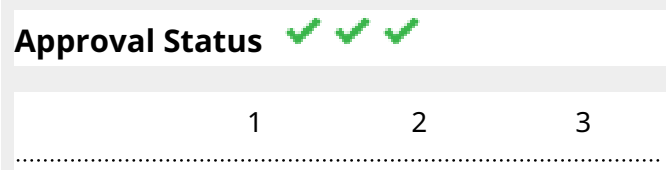 \\ version 3 \\ (revision) \\ 15 Sep 2020 \\ version 2 \\ (revision) \\ 24 Aug 2020 \\ version 1 \\ 02 Apr 2020
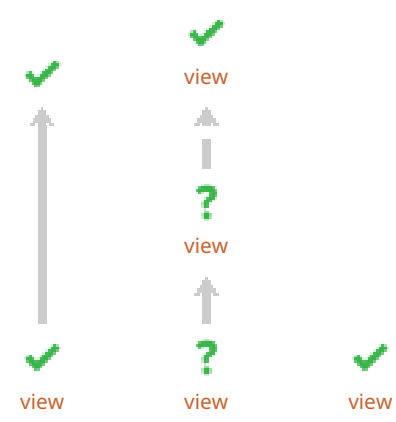 \\ 1. Noor Buchholz, U-merge Ltd. (Urology for Emerging Countries), London, UK \\ Andreas Bourdoumis (Dennine Acute Hospitals NHS Trust, Manchester, UK \\ 2. Mohammed S. ElSheemy ${ }^{1 D}$, Kasr Al-Ainy Hospitals, Cairo University, Cairo, Egypt \\ 3. Doddy Soebadi ID, Airlangga University, \\ Surabaya, Indonesia \\ Any reports and responses or comments on the}


Keywords

Complication rate, Percutaneous nephrolithotomy, Prone, Stone free rate, Supine article can be found at the end of the article.
Corresponding author: Ponco Birowo (ponco.birowo@gmail.com)

Author roles: Birowo P: Conceptualization, Data Curation, Formal Analysis, Funding Acquisition, Investigation, Methodology, Project Administration, Resources, Supervision, Validation, Visualization, Writing - Review \& Editing; Tendi W: Data Curation, Formal Analysis, Investigation, Resources, Software, Validation, Visualization, Writing - Original Draft Preparation; Widyahening IS: Data Curation, Formal Analysis, Methodology, Supervision, Writing - Review \& Editing; Rasyid N: Conceptualization, Formal Analysis, Methodology, Validation, Writing - Review \& Editing; Atmoko W: Conceptualization, Data Curation, Formal Analysis, Methodology, Project Administration, Resources, Validation, Writing - Review \& Editing

Competing interests: No competing interests were disclosed.

Grant information: The author(s) declared that no grants were involved in supporting this work.

Copyright: ( 2020 Birowo P et al. This is an open access article distributed under the terms of the Creative Commons Attribution License , which permits unrestricted use, distribution, and reproduction in any medium, provided the original work is properly cited.

How to cite this article: Birowo P, Tendi W, Widyahening IS et al. Supine versus prone position in percutaneous nephrolithotomy: a systematic review and meta-analysis [version 1; peer review: 2 approved, 1 approved with reservations] F1000Research 2020, 9 :231 https://doi.org/10.12688/f1000research.22940.1

First published: 02 Apr 2020, 9:231 https://doi.org/10.12688/f1000research.22940.1 


\section{Introduction}

Nephrolithiasis is one of the most common urological diseases worldwide. It is defined as a condition where mineral deposits are found in the kidney, either free in the renal calyces and pelvis or attached on the renal papillae ${ }^{1}$. The prevalence is varied between regions, ranging between $7-13 \%$ in North America, 5-9\% in Europe, and 1-5\% in Asia ${ }^{2}$. The most common stone composition is calcium, comprising about $80 \%$ of all urolithiasis ${ }^{3}$.

Depending on stone burden, the treatment of nephrolithiasis also has a wide range of options. Active management includes extracorporeal shockwave lithotripsy (ESWL), retrieval by ureteroscopy (URS), and percutaneous nephrolithotomy (PCNL). The current guideline generally recommends ESWL for smaller stones (up to $20 \mathrm{~mm}$ ) and PCNL for larger stones (>20 mm) regardless of the location inside the kidney ${ }^{4}$.

While PCNL has higher free stone rates with a similar recurrence and complication rate compared with ESWL, this procedure also has its own preparation including a guiding system, anesthesia, and positioning of the patient. The conventional position of PCNL is prone, which allows direct access to the posterior calyx with minimal risk of bowel puncture. However, this positioning method limits the possibility of switching anesthesia from regional to general. The alternative position is supine, which allows general anesthesia switching and combination technique of antegrade and retrograde approaches. Moreover, this position is also more preferred in patients with cardiac comorbidity. However, working space and the possibility of multiple channels are limited ${ }^{5}$. The aim of this study is to determine whether one position is more superior than the other, by comparing efficacy and safety profiles using a systematic review and meta-analysis approach.

\section{Methods}

\section{Description of condition and intervention}

The target population in this study is patients with renal stone of $20 \mathrm{~mm}$ or more in size who underwent PCNL. The intervention to the patients is PCNL in prone position, compared with PCNL in supine position. Prone is a classic position in PCNL procedure, described in 1976 when PCNL was first introduced. The original prone position consists of a two-stage procedure. The first stage is in supine position, where anesthesia is given and retrograde access to the upper urinary tract is established. The patient is then repositioned to a prone position, and supports are placed under the thorax and upper abdomen. All pressure points are also padded ${ }^{6}$.

In contrast, a supine prone only needs one stage, in which the patient is placed supine with ipsilateral flank held up with a 3-liter saline bag. This original position was first introduced by Valdivia-Uria et al. and has been modified over time ${ }^{7}$. One popular modification of Valdivia position is the Galdakao modification. This position is slightly more lateral; the contralateral leg of the patient is flexed and abducted, while the ipsilateral leg is extended. A 3-liter bag is also placed to raise the flank $^{6}$.
Apart from the Valdivia position and its modifications, a complete supine position was also introduced by Falahatkar et al. ${ }^{8}$ This position does not require an elevation of the flank. The patient is simply put in a supine position at the edge of the table, with legs extended. The patient's arms are stretched, abducted and supported.

The outcome of this study is the efficacy of both positions, determined by stone free rate and safety profile, determined by the occurrence of major complications.

\section{Database searching and literature screening}

A systematic search was carried out with the date last searched in 14 February 2020, using the database from MEDLINE, with keywords of " $((($ supine[Title/Abstract]) AND prone[Title/ Abstract])) AND ((PCNL[Title/Abstract]) OR percutaneous nephrolithotomy[Title/Abstract])", and Cochrane library, with keywords of "prone in Title Abstract Keyword AND supine in Title Abstract Keyword AND PCNL in Title Abstract Keyword", and Google Scholar with keywords of "prone AND supine AND percutaneous nephrolithotomy". After we identified the articles, we removed the duplicates and further screened the articles. The reporting is based on Preferred Reporting Items for Systematic Reviews and Meta-Analyses (PRISMA) algorithm.

\section{Study selection}

Two reviewers (PB and WT) independently appraised the articles, and a discussion was conducted when disagreement occurred. The relevance of the articles is determined by reading through the titles and abstracts. The inclusion criterion is a comparative study between the supine and prone position in PCNL procedure, and the articles were written in English. The exclusion criteria are non-comparative studies, studies that combine PCNL with other techniques of stone extraction such as URS or retrograde intrarenal surgery, not focused on comparing supine and prone position in PCNL, and inclusion of confounding factors such as a difference in guiding method when performing PCNL in each position, since this difference will lead to intervention bias. The quality of each article included were then tested using Jadad scale for randomized controlled trials (RCT) and Newcastle-Ottawa scale for non-RCTs ${ }^{9,10}$.

\section{Data extraction}

Data extraction from the articles was performed by two authors (NR and WA), and any disagreement was settled by consensus. The variables extracted from the articles included the first author's name, year of publication, stone free rate, percentage of major complications, length of hospital stay, and mean operation time. Stone free condition is defined as the absence of residual fragments of $\leq 4 \mathrm{~mm}$ after procedure. Major complications are defined as those with a Clavien score of III or more ${ }^{11}$.

\section{Statistical analysis}

Meta-analysis was performed by Review Manager 5.3. The results were described as odds ratio (OR) with $95 \%$ confidence interval (CI) for dichotomous variables, and as a mean difference with $95 \%$ CI for continuous variables. Heterogeneity was analyzed using a Chi square and $\mathrm{I}^{2}$ test. The data was analyzed using 
the random-effect model when $\mathrm{I}^{2}>25 \%$, and fixed-effect model when $\mathrm{I}^{2}$ is less than $25 \%$. The analysis is considered statistically significant when $\mathrm{p}$ value is less than 0.05 . For studies that provided the minimum and maximum value instead of standard deviation (SD) for the mean difference analysis, estimated SD were calculated with the formula derived from a study by Walter and Yao (2007) ${ }^{12}$. In addition, for studies that provided 95\% Confidence Interval (CI) instead of SD, the value of SD was calculated using the formula described in the Cochrane Handbook $^{13}$

\section{Results}

Literature search

Following the result of article screening and the application of exclusion criteria, a total of 156 articles were found from the three databases. After removing duplicates, a total of 131 studies were screened for relevance, of which only 11 articles were included in qualitative and quantitative analysis (Figure 1).
Study characteristics

Quality assessment of the articles is shown in Table 1. Study characteristics, including the study design, mean age, and stone burden, is shown in Table 2.

\section{Stone free rate}

All 11 studies reported the stone free rate of both supine and prone groups. A meta-analysis of these studies showed that there was a statistically significant lower stone free rate in the supine group (OR: 0.74; 95\% CI: 0.66 - 0.83; p<0.00001; Figure 2).

\section{Major complication rate}

Major complication rate is defined as Clavien score of 3 of more in this study. There were only 5 articles that reported the complication rate using Clavien score. Figure 3 showed that there is a statistically significant lower complication rate in the supine group (OR: 0.70; 95\% CI: $0.51-0.96 ; \mathrm{p}=0.03$ ).
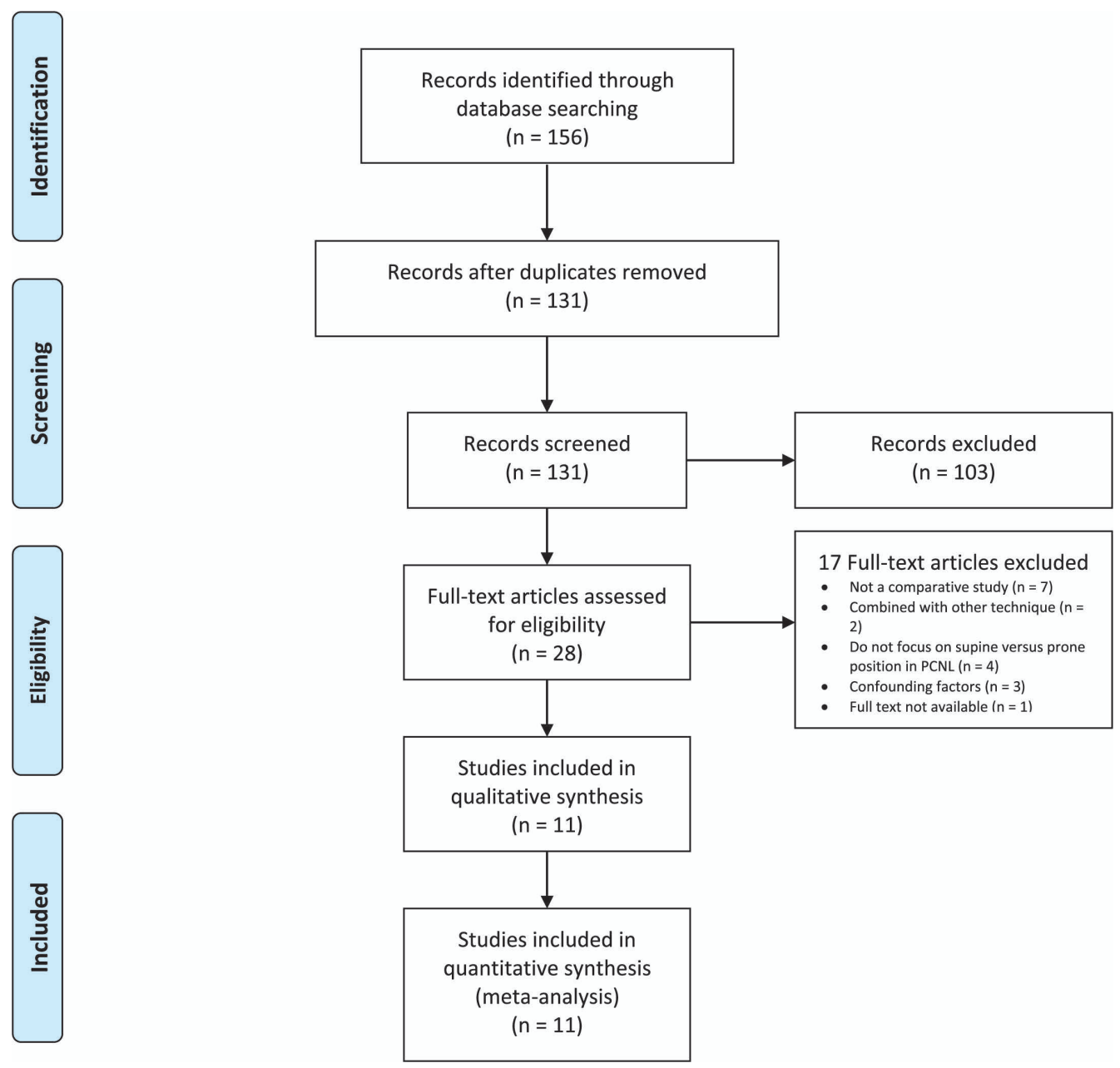

Figure 1. PRISMA method of article screening. 
Table 1. Quality assessment of the articles included. RCT, randomized controlled trial.

\begin{tabular}{|c|c|c|c|}
\hline \multirow[b]{2}{*}{ Articles } & \multirow[b]{2}{*}{$\begin{array}{l}\text { Study } \\
\text { design }\end{array}$} & \multicolumn{2}{|c|}{ Quality assessment } \\
\hline & & $\begin{array}{l}\text { Jadad } \\
\text { scale }\end{array}$ & $\begin{array}{l}\text { Newcastle- } \\
\text { Ottawa } \\
\text { scale }\end{array}$ \\
\hline Melo PAS, et al. (2019) ${ }^{8}$ & Cohort & - & 8 \\
\hline Gokce MI, et al. $(2017)^{14}$ & Cohort & - & 8 \\
\hline Mahmoud M, et al. (2017) & $\mathrm{RCT}$ & 2 & - \\
\hline Wood GJA, et al. $(2017)^{16}$ & Cohort & - & 7 \\
\hline Astroza G, et al. (2013) ${ }^{17}$ & Cohort & - & 6 \\
\hline Kan RW, et al. (2013) ${ }^{18}$ & Cohort & - & 8 \\
\hline Karami H, et al. (2013) ${ }^{19}$ & $\mathrm{RCT}$ & 1 & - \\
\hline Sanguedolce F, et al. (2013) ${ }^{20}$ & Cohort & - & 6 \\
\hline Arrabal-Martin M, et al. (2012) & Cohort & - & 7 \\
\hline Wang Y, et al. $(2012)^{22}$ & Cohort & - & 8 \\
\hline Valdivia JG, et al. (2011) & Cohort & - & 8 \\
\hline
\end{tabular}

Table 2. Characteristics of studies included.

\begin{tabular}{|c|c|c|c|c|c|c|}
\hline \multirow[t]{2}{*}{ Articles } & \multicolumn{2}{|c|}{ Cases (n) } & \multicolumn{2}{|c|}{ Mean age (years) } & \multicolumn{2}{|c|}{ Stone size $\left(\mathrm{mm} / \mathrm{mm}^{2}\right)$} \\
\hline & Supine & Prone & Supine & Prone & Supine & Prone \\
\hline Melo PAS, et al. (2019) & 294 & 99 & 49.14 & 47.66 & 29.76 & 30.34 \\
\hline Gokce MI, et al. (2017) & 39 & 48 & 47.5 & 49.2 & 47.3 & 45.6 \\
\hline Mahmoud M, et al. (2017) & 20 & 20 & 42.35 & 41.15 & 27.1 & 25.7 \\
\hline Wood GJA, et al. (2017) & 28 & 104 & 45.89 & 44.98 & - & - \\
\hline Astroza G, et al. (2013) & 232 & 1079 & 51.8 & 49.8 & - & - \\
\hline Kan RW, et al. (2013) & 25 & 35 & 67 & 63 & 36.9 & 44.8 \\
\hline Karami H, et al. (2013) & 50 & 50 & 44.4 & 41.5 & 28.2 & 28.3 \\
\hline Sanguedolce F, et al. (2013) & 65 & 52 & 53 & 49 & 20.6 & 18.1 \\
\hline Arrabal-Martin M, et al. (2012) & 24 & 32 & 49 & 47 & 510 & 530 \\
\hline Wang Y, et al. (2012) & 6 & 12 & 44.8 & 43.8 & 36 & 33 \\
\hline Valdivia JG, et al. (2011) & 1138 & 4637 & 51 & 48.8 & 470.6 & 449.1 \\
\hline Total patients & 1921 & 6168 & - & - & - & - \\
\hline
\end{tabular}

\section{Length of hospital stay}

There were nine studies that reported mean days of hospital stay in both groups. The forest plot in Figure 4 shows that there is no difference in the length of hospital stay between groups (Mean difference: -0.01 ; 95\% CI: $-0.27-0.24$; $\mathrm{p}=0.92$ ).

\section{Mean operation time}

Mean operation time was reported in all studies. The meta-analysis in this parameter showed that there is no difference in mean operation time between these two groups (Mean difference: -2.68 ; 95\% CI: $-12.36-7.00 ; \mathrm{p}=0.59$; Figure 5).

\section{Discussion}

According to our review, supine and prone position during PCNL share a similar mean operation time and duration of hospital stay. This result is important so that the surgeons will be able to confidently decide the position based on their experiences and the patient's comorbidities. In addition, the 


\begin{tabular}{|c|c|c|c|c|c|c|c|c|c|c|}
\hline Study or Subgroup & \multicolumn{2}{|c|}{ Supine } & \multicolumn{2}{|c|}{ Prone } & \multicolumn{3}{|c|}{ Odds Ratio } & \multicolumn{2}{|c|}{$\begin{array}{c}\text { Odds Ratio } \\
\text { M-H, Fixed, } 95 \% \mathrm{Cl}\end{array}$} & \\
\hline Arrabal-Martin M, et al. (2012) & 19 & 24 & 24 & 32 & $0.7 \%$ & $1.27[0.36,4.51]$ & & & & \\
\hline Astroza G, et al. (2013) & 112 & 232 & 639 & 1079 & $19.0 \%$ & $0.64[0.48,0.85]$ & & $\rightarrow-$ & & \\
\hline Gokce Ml, et al. (2017) & 25 & 39 & 29 & 48 & $1.5 \%$ & $1.17[0.49,2.80]$ & & & & \\
\hline Kan RW, et al. (2013) & 17 & 25 & 16 & 35 & $0.7 \%$ & $2.52[0.86,7.37]$ & & & & \\
\hline Karami H, et al. (2013) & 43 & 50 & 46 & 50 & $1.0 \%$ & $0.53[0.15,1.95]$ & & & & \\
\hline Mahmoud M, et al. (2017) & 16 & 20 & 17 & 20 & $0.6 \%$ & $0.71[0.14,3.66]$ & & & & \\
\hline Melo PAS, et al. (2019) & 124 & 294 & 37 & 99 & $5.2 \%$ & $1.22[0.77,1.95]$ & & & - & \\
\hline Sanguedolce $F$, et al. (2013) & 57 & 65 & 47 & 52 & $1.0 \%$ & $0.76[0.23,2.47]$ & & - & & \\
\hline Valdivia JG, et al. (2011) & 799 & 1138 & 3571 & 4637 & $68.0 \%$ & $0.70[0.61,0.81]$ & & $\square$ & & \\
\hline Wang Y, et al. (2012) & 5 & 6 & 11 & 12 & $0.2 \%$ & $0.45[0.02,8.83]$ & & & & \\
\hline Wood G.JA, et al. (2017) & 15 & 28 & 66 & 104 & $2.1 \%$ & $0.66[0.29,1.54]$ & & & & \\
\hline Total $(95 \% \mathrm{Cl})$ & & 1921 & & 6168 & $100.0 \%$ & $0.74[0.66,0.83]$ & & $\downarrow$ & & \\
\hline Total events & 1232 & & 4503 & & & & & & & \\
\hline $\begin{array}{l}\text { Heterogeneity: } \mathrm{Chi}^{2}=13.02, \mathrm{~d} \\
\text { Test for overall effect: } Z=4.98\end{array}$ & $\begin{array}{l}10(P= \\
P<0.000\end{array}$ & $\begin{array}{l}0.22) ; 1^{2} \\
01)\end{array}$ & $=23 \%$ & & & & 0.01 & $\begin{array}{c}0.1 \\
\text { Favours P }\end{array}$ & Favou & $\begin{array}{l}10 \\
\text { Supine }\end{array}$ \\
\hline
\end{tabular}

Figure 2. Forest plot comparing stone free rate in prone and supine groups.

\begin{tabular}{|c|c|c|c|c|c|c|c|c|c|c|}
\hline \multirow{2}{*}{$\begin{array}{l}\text { Study or Subgroup } \\
\text { Gokce Ml, et al. (2017) }\end{array}$} & \multicolumn{2}{|c|}{ Supine } & \multicolumn{2}{|c|}{ Prone } & Weight & $\begin{array}{c}\text { Odds Ratio } \\
\text { M-H, Fixed, } 95 \% \mathrm{Cl}\end{array}$ & \multicolumn{4}{|c|}{$\begin{array}{c}\text { Odds Ratio } \\
\text { M-H, Fixed, } 95 \% \mathrm{Cl}\end{array}$} \\
\hline & 0 & 39 & 2 & 48 & $2.3 \%$ & $0.24[0.01,5.05]$ & & & & \\
\hline Melo PAS, et al. (2019) & 23 & 294 & 9 & 99 & $12.6 \%$ & $0.85[0.38,1.90]$ & & & & \\
\hline Valdivia JG, et al. (2011) & 37 & 1126 & 202 & 4585 & $78.1 \%$ & $0.74[0.52,1.05]$ & & & & \\
\hline Wang Y, et al. (2012) & 0 & 6 & 0 & 12 & & Not estimable & & & & \\
\hline Wood G.JA, et al. (2017) & 1 & 28 & 17 & 104 & $7.1 \%$ & $0.19[0.02,1.49]$ & & & - & \\
\hline Total $(95 \% \mathrm{Cl})$ & & 1493 & & 4848 & $100.0 \%$ & $0.70[0.51,0.96]$ & & & & \\
\hline Total events & 61 & & 230 & & & & & & & \\
\hline $\begin{array}{l}\text { Heterogeneity: } \mathrm{Chi}^{2}=2.3 \\
\text { Test for overall effect: } Z=\end{array}$ & $\begin{array}{l}d f=3(P \\
19(P=0\end{array}$ & $\begin{array}{l}=0.51 \\
0.03)\end{array}$ & $;\left.\right|^{2}=0 \%$ & & & & 0.01 & $\begin{array}{c}0.1 \\
\text { Favours Supine }\end{array}$ & $\begin{array}{c}10 \\
\text { Favours Prone }\end{array}$ & 100 \\
\hline
\end{tabular}

Figure 3. Forest plot comparing major complication rate in prone and supine groups.

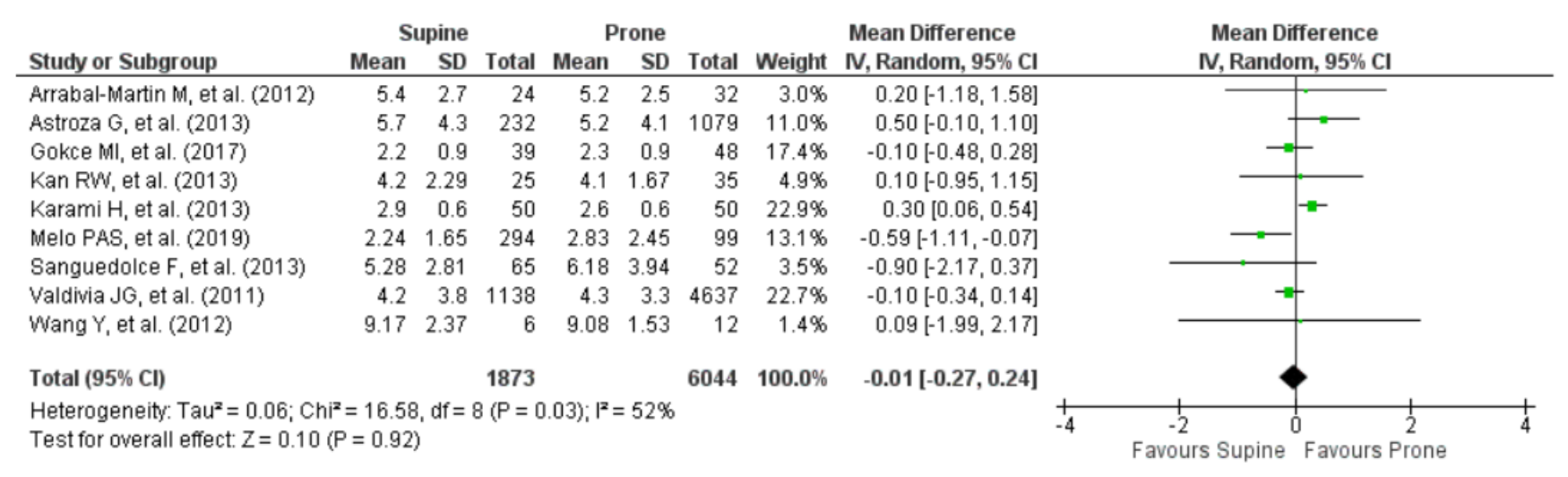

Figure 4. Forest plot comparing length of hospital stay in prone and supine groups. 


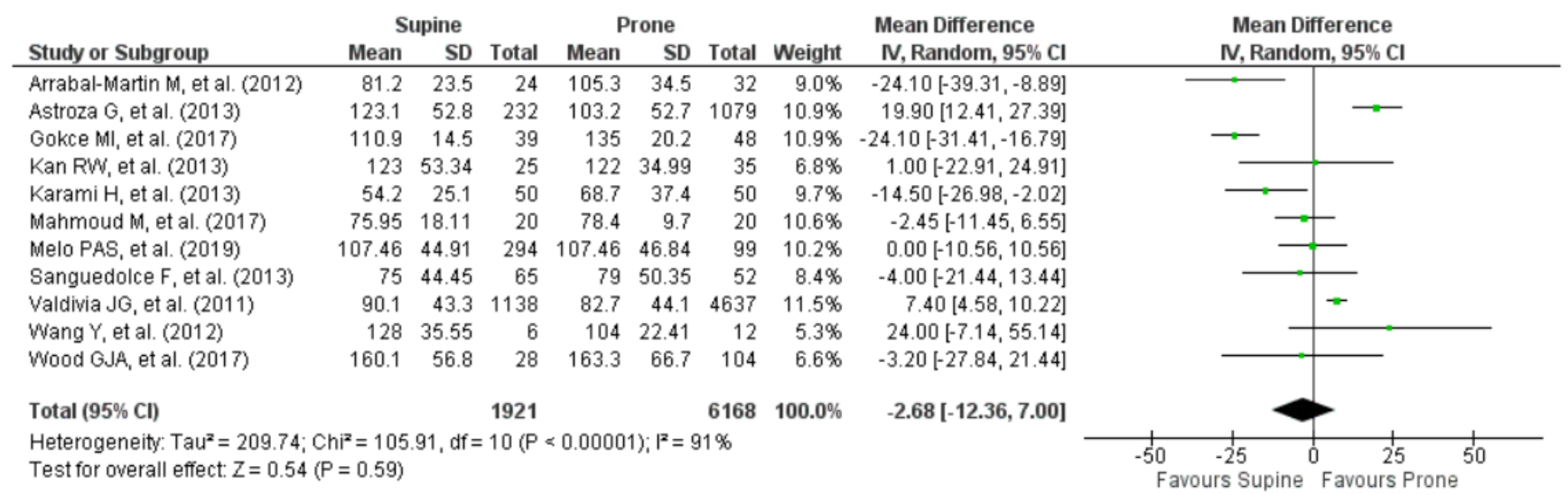

Figure 5. Forest plot comparing mean operation time in prone and supine groups.

study conducted by Melo et al. showed similarities between both positions in terms of the number of puncture tracts, blood transfusion rate, and mean drop in hemoglobin level ${ }^{11}$.

However, despite the similarities, this study also found significant differences between these two groups. The authors choose stone free rate and major complication as the main outcome of this article to help identify which position is safe in PCNL and whether there is a difference in the efficacy. Interestingly, both of these outcomes were statistically different.

Our study found that the supine position had a lower major complication rate than prone position. Literature revealed that the original (Valdivia) position is reportedly safe, and endoscopic instruments can be moved more freely because the puncture site of the abdominal wall is performed more laterally and away from the lumbar muscles. The tract in this position also preserves a low pressure in the renal pelvis, reducing the risk of fluid absorption. Moreover, risk of colonic puncture might be reduced because the bowel is not pressed towards the kidney. Should a rigid ureteroscopy be needed simultaneously with PCNL, a modified Valdivia position can be performed by flexing and supporting the patient's ipsilateral leg, and the contralateral leg descended. The supine position also has the advantage of easier management of cardiac and respiratory emergencies ${ }^{6}$.

Moreover, the Galdakao-modified position allows more instrument manipulation than the original supine position. Furthermore, it also enables simultaneous retrograde access to the kidney and there is no need to reposition thus the asepsis and antisepsis procedure needs to be performed only once ${ }^{6}$.

In the complete supine position, the lack of flank support allows more feasible access to the upper pole of the kidney because there is no risk of cephalad sliding of the kidney, as observed in the supine position with flank support ${ }^{6}$. The supine position also has the advantages of easier access to the upper pole after lower pole puncture ${ }^{23}$.
However, it should also be noted that while there are many advantages to the supine position, the flank in this position is not fully exposed, therefore reducing the possibility of multiple access when needed. In addition, the state of low compressed abdomen allows the kidney to move more freely, making the navigation of the instrument towards the kidney more challenging, and the chance of failed access is higher ${ }^{6,7,16}$.

Additionally, our study found that stone free rate was significantly higher in prone position. The major advantage in this position is the fully exposed lumbar area. This allows a possibility of several puncture sites, and easier access to the upper pole kidney. Moreover, the working area is greater, providing enough space for instrument manipulation ${ }^{6}$.

However, the two-stage nature of this position usually prolongs the operating time, and a prone position makes it difficult for the anesthetists to attend cardio-respiratory emergency. The risk of ocular complications has also been described because of the increase in intra-ocular pressure ${ }^{6}$.

The limitation in our study is that the number of articles providing data of major complication rate in terms of Clavien score was limited and there were too many heterogeneities in the length of hospital stay and mean operation time variables. Therefore, the authors believe that another comprehensive study should be performed in urology centers in which the surgeons excel in both supine and prone position when performing PCNL and have a larger sample size.

The implication of this study is that it exposed the benefit and disadvantages of both supine and prone position, which in turn can be used as a decision guide for clinicians who want to perform PCNL.

\section{Conclusion}

In conclusion, the prone position leads to a higher stone free rate than supine position. However, in terms of safety profile, 
supine position provides a better choice than the prone position. There is no difference in both the length of hospital stay and mean operation time between prone and supine position. Therefore, it can be inferred that there is no position that has absolute superiority and it is important to note that both supine and prone position in PCNL procedure have their respective advantages and disadvantages. Thus, the decision of choosing the position when performing PCNL should be based on clinical status of the patient and the experience of the surgeon.

\section{Data availability}

\section{Underlying data}

All data underlying the results are available as part of the article and no additional source data are required.

\section{Reporting guidelines}

Open Science Framework: PRISMA checklist for article 'Supine versus prone position in percutaneous nephrolithotomy: a systematic review and meta-analysis', https://doi.org/10.17605/OSF. $\mathrm{IO} / 23 \mathrm{GND}^{24}$

Data are available under the terms of the Creative Commons Zero "No rights reserved" data waiver (CCO 1.0 Public domain dedication)

\section{Acknowledgements}

The authors would like to thank you to the Cipto Mangunkusumo National Hospital for the support and permission for the authors to finish the production of this article.
1. Khan SR, Pearle MS, Robertson WG: Kidney stones. Nat Rev Dis Primers. 2016; 2: 16008 .

PubMed Abstract | Publisher Full Text | Free Full Text

2. Sorokin I, Mamoulakis C, Miyazawa K, et al.: Epidemiology of stone disease across the world. World J Urol. 2017; 35(9): 1301-20. PubMed Abstract | Publisher Full Text

3. Alelign T, Petros B: Kidney Stone Disease: An Update on Current Concepts. Adv Urol. 2018; 2018: 3068365.

PubMed Abstract | Publisher Full Text | Free Full Text

4. Turk C, Skolarikos A, Neisius A, et al.: EAU Guidelines on Urolithiasis. The Netherlands: EAU Guidelines Office; 2019.

5. Ganpule AP, Vijayakumar M, Malpani A, et al:: Percutaneous nephrolithotomy (PCNL) a critical review. Int J Surg. 2016; 36(Pt D): 660-664. PubMed Abstract | Publisher Full Text

6. Karaolides T, Moraitis K, Bach C, et al.: Positions for percutaneous nephrolithotomy: Thirty-five years of evolution. Arab J Urol. 2012; 10(3): 307-16. PubMed Abstract | Publisher Full Text | Free Full Text

7. Valdivia JG, Scarpa RM, Duvdevani M, et al: Supine versus prone position during percutaneous nephrolithotomy: a report from the clinical research office of the endourological society percutaneous nephrolithotomy global study. J Endourol. 2011; 25(10): 1619-25. PubMed Abstract | Publisher Full Text

8. Falahatkar S, Moghaddam AA, Salehi M, et al:: Complete supine percutaneous nephrolithotripsy comparison with the prone standard technique. $J$ Endourol. 2008; 22(11): 2513-7.

PubMed Abstract | Publisher Full Text

9. Cho HJ, Chung JH, Jo JK, et al.: Assessments of the quality of randomized controlled trials published in International Journal of Urology from 1994 to 2011. Int J Urol. 2013; 20(12): 1212-9. PubMed Abstract | Publisher Full Text

10. Luchini C, Stubbs B, Solmi M, et al.: Assessing the quality of studies in metaanalyses: advantages and limitations of the newcastle ottawa scale. World J Meta Anal. 2017; 5(4): 80-4. Publisher Full Text

11. Melo PAS, Vicentini FC, Perrella R, et al:: Comparative study of percutaneous nephrolithotomy performed in the traditional prone position and in three different supine positions. Int Braz J Urol. 2019; 45(1): 108-17. PubMed Abstract | Publisher Full Text | Free Full Text

12. Walter $\mathrm{SD}$, Yao $\mathrm{X}$ : Effect sizes can be calculated for studies reporting ranges for outcome variables in systematic reviews. J Clin Epidemiol. 2007; 60(8): 849-52.

PubMed Abstract | Publisher Full Text

13. Higgins JPT, Green S: Cochrane Handbook for Systematic Reviews of
Interventions. Version 5.1.0 [updated March 2011]. The Cochrane Collaboration; 2011. Reference Source

14. Gokce MI, Ibis A, Sanci A, et al:: Comparison of supine and prone positions fo percutaneous nephrolithotomy in treatment of staghorn stones. Urolithiasis. 2017; 45(6): 603-8.

PubMed Abstract | Publisher Full Text

15. Mahmoud M, Abdel AA, Abdel AM, et al:: Flank suspended supine position versus standard supine and prone position in percutaneous nephrolithotomy. $J$ Endourol. 2017; 31: A95-A98.

16. Wood GJA, Torricelli FCM, Vicentini FC, et al.: Supracostal punctures in supine percutaneous nephrolithotomy are safe. Can J Urol. 2017; 24(2): 8749-53. PubMed Abstract

17. Astroza G, Lipkin M, Neisius A, et al:: Effect of supine vs prone position on outcomes of percutaneous nephrolithotomy in staghorn calculi: results from the Clinical Research Office of the Endourology Society Study. Urology. 2013; 82(6): 1240-4.

PubMed Abstract | Publisher Full Text

18. Kan RW, Fu KK, Wong BT, et al.: Percutaneous nephrostomy, nephrolithotomy and combined ureteroscopic lithotripsy using the supine approach. Hong Kong Med J. 2013; 19(2): 142-9. PubMed Abstract

19. Karami H, Mohammadi R, Lotfi B: A study on comparative outcomes of percutaneous nephrolithotomy in prone, supine, and flank positions. World $J$ Urol. 2013; 31(5): 1225-30. PubMed Abstract | Publisher Full Text

20. Sanguedolce F, Breda A, Millan F, et al:: Lower pole stones: prone PCNL versus supine PCNL in the International Cooperation in Endourology (ICE) group experience. World J Urol. 2013; 31(6): 1575-80. PubMed Abstract | Publisher Full Text

21. Arrabal-Martin M, Arrabal-Polo MA, Lopez-Leon V, et al:: The oblique supine decubitus position: technical description and comparison of results with the prone decubitus and dorsal supine decubitus positions. Urol Res. 2012; 40(5) 587-92.

PubMed Abstract | Publisher Full Text

22. Wang $\mathrm{Y}$, Hou $\mathrm{Y}$, Jiang $\mathrm{F}$, et al.: Percutaneous nephrolithotomy for staghorn stones in patients with solitary kidney in prone position or in completely supine position: a single-center experience. Int Braz J Urol. 2012; 38(6): 788-94. PubMed Abstract | Publisher Full Text

23. Sofer M, Giusti G, Proietti S, et al: Upper Calyx Approachability through a Lower Calyx Access for Prone Versus Supine Percutaneous Nephrolithotomy. $J$ Urol. 2016; 195(2): 377-82.

PubMed Abstract | Publisher Full Text

24. Tendi W: Supine versus Prone Position in Percutaneous Nephrolithotomy: A Systematic Review and Meta-Analysis. 2020 http://dx.doi.org/10.17605/OSF.IO/23GND 


\section{Open Peer Review}

\section{Current Peer Review Status:}

\section{Version 1}

Reviewer Report 13 December 2021

https://doi.org/10.5256/f1000research.25326.r64021

(C) 2021 Soebadi D. This is an open access peer review report distributed under the terms of the Creative Commons Attribution License, which permits unrestricted use, distribution, and reproduction in any medium, provided the original work is properly cited.

\section{Doddy Soebadi}

Department of Urology, Faculty of Medicine, Airlangga University, Surabaya, Indonesia

A good review. We do need the evidence based for choosing the method.

The authors could also state their opinions concerning the training of the procedures, whether the two methods have to be taught or directly to one method.

In conclusion, it can also be stated the positive and negative sides of each procedures, in consideration the needs for training.

Congratulations to the authors.

Are the rationale for, and objectives of, the Systematic Review clearly stated? Yes

Are sufficient details of the methods and analysis provided to allow replication by others? Yes

Is the statistical analysis and its interpretation appropriate?

Yes

Are the conclusions drawn adequately supported by the results presented in the review? Yes

Competing Interests: No competing interests were disclosed.

Reviewer Expertise: Stone disease, male infertility, andrology.

I confirm that I have read this submission and believe that I have an appropriate level of expertise to confirm that it is of an acceptable scientific standard. 
Reviewer Report 31 July 2020

https://doi.org/10.5256/f1000research.25326.r67732

(C) 2020 ElSheemy M. This is an open access peer review report distributed under the terms of the Creative Commons Attribution License, which permits unrestricted use, distribution, and reproduction in any medium, provided the original work is properly cited.

\section{Mohammed S. ElSheemy}

Urology department, Kasr Al-Ainy Hospitals, Cairo University, Cairo, Egypt

The authors presented their meta-analyses comparing prone versus supine PCNL for the management of renal stones $>2 \mathrm{~cm}$. They reported a higher SFR with prone technique but a better safety profile with supine technique. However, there are many points that require more details especially in the results and discussion section. The authors did not comment on studies heterogenousities or quality. Many points were not presented in each study (detailed in the comments on the results and discussion section). The authors did not discuss previous metaanalyses on the same issue nor clarifying the addition or difference in the current study.

\section{Introduction:}

The authors reported that: [While PCNL has higher free stone rates with a similar recurrence and complication rate compared with ESWL,...]. This should be cited. Additionally, the complication rates are different between both procedures. Similarly, the recurrence rate is different.

\section{Method:}

The authors should clarify the age of patients and the design of the study (RCT or cohort) in the inclusion criteria.

\section{Results:}

The authors did not comment on the quality of included studies as well as their heterogenicity.

Figure 1:

The authors should clarify why 103 studies were excluded out of 131.

The authors should perform a separate analysis (or at least a separate comment) for blood transfusion, sepsis, pleural effusion or visceral injury complications.

Table 2: the authors should add many points to describe each study adequately including:

Number and shape of stone

SFR for each study.

The method and timing for evaluation of SFR.

If SFR was calculated after first session or after 2nd look PCNL.

The complications for each technique (and its rate). 
If any procedure was Mini-PCNL and the caliber of used renal track (sheath).

If there were congenital renal anomalies.

Lithotripsy technique.

Operative imaging modality.

\section{Discussion:}

The authors should give more details of the included studies.

The authors should discuss previous meta-analyses comparing both procedures. Additionally, the authors should compare the results of the present study to previous metaanalyses clarifying any difference and any addition.

Are the rationale for, and objectives of, the Systematic Review clearly stated? Yes

Are sufficient details of the methods and analysis provided to allow replication by others? No

Is the statistical analysis and its interpretation appropriate?

I cannot comment. A qualified statistician is required.

Are the conclusions drawn adequately supported by the results presented in the review? Yes

Competing Interests: No competing interests were disclosed.

Reviewer Expertise: Urolithiasis, endourology, PCNL, Mini-PCNL, URS, SWL

I confirm that I have read this submission and believe that I have an appropriate level of expertise to confirm that it is of an acceptable scientific standard, however I have significant reservations, as outlined above.

Author Response 15 Aug 2020

Ponco Birowo, Faculty of Medicine Universitas Indonesia / Cipto Mangunkusumo Hospital, Jakarta Pusat, Indonesia

\section{Introduction}

Reviewers' comment:

1. The authors reported that: [While PCNL has higher free stone rates with a similar recurrence and complication rate compared with ESWL,...]. This should be cited.

Additionally, the complication rates are different between both procedures. Similarly, the recurrence rate is different.

Authors' response:

1. Thank you very much for the comment, we have added the citation of the statement 
mentioned in the introduction section: [While PCNL has higher free stone rates with a similar recurrence and complication rate compared with ESWL, this procedure also has its own preparation including a guiding system, anesthesia, and positioning of the patient]. The citation was the reference number 5, which is [Ganpule AP, Vijayakumar M, Malpani A, Desai MR. Percutaneous nephrolithotomy (PCNL) a critical Methods review. Int J Surg. 2016; 36(Pt D): 660-4.] (Page 3, Paragraph 3, Introduction section).

Reviewers' comment:

1. The authors should clarify the age of patients and the design of the study (RCT or cohort) in the inclusion criteria.

Authors' response:

1. Thank you very much for the comment, we have revised the inclusion criteria accordingly. (Page 4, Paragraph 6, Methods section, subsection Study Selection).

\section{Results}

Reviewers' comment:

1. The authors did not comment on the quality of included studies as well as their heterogenicity.

2. Figure 1:

The authors should clarify why 103 studies were excluded out of 131.

3. The authors should perform a separate analysis (or at least a separate comment) for blood transfusion, sepsis, pleural effusion or visceral injury complications.

4. Table 2: the authors should add many points to describe each study adequately including:

Number and shape of stone

SFR for each study.

The method and timing for evaluation of SFR.

If SFR was calculated after first session or after 2nd look PCNL.

The complications for each technique (and its rate).

If any procedure was Mini-PCNL and the caliber of used renal track (sheath).

If there were congenital renal anomalies.

Lithotripsy technique.

Operative imaging modality.

Authors' response:

1. Thank you very much for the comment, we have added a summary of the quality assessment of each article (Page 5, Paragraph 5, Results section, subsection Study Characteristics). Furthermore, we also showed the heterogeneity of each variable measured in this article (Page 9-11, Results section, subsection Stone Free Rate, Major Complication Rate, Length of Hospital Stay, and Mean Operation Time).

2. Thank you very much for the kind comment. The reason of which 103 articles were excluded because as we screened through all the titles and abstracts, we only found 28 articles that has the main topic of our interest, which is a study with either trial design or observational study (Page 5, Paragraph 4, Results section, subsection Literature Search).

3. Thank you very much for the suggestion, we have added a further separate analysis 
regarding the need of blood transfusion, sepsis, and visceral injuries complication presented in a forest plot (Page 10, Results section, Figure 4).

4. Thank you very much for the suggestion, we have added more details on the Table 2 accordingly (Page 7, Results section, Table 2).

Discussion

Reviewers' comment:

1. The authors should give more details of the included studies.

2. The authors should discuss previous meta-analyses comparing both procedures. Additionally, the authors should compare the results of the present study to previous meta-analyses clarifying any difference and any addition.

Authors' response:

1. Thank you very much for the kind comment, we have added more detail of our included studies on the discussion section (Page 11, Paragraph 3, Discussion section).

2. Thank you for the suggestion, we have added the comparison of the previous metaanalyses to our study (Page 12, Paragraph 6, Discussion section). Regarding to this addition, we have added the references accordingly (Page 15, References number 24 and 25).

Competing Interests: The authors declare that there is no competing interests to disclose

Reviewer Report 06 April 2020

https://doi.org/10.5256/f1000research.25326.r61982

(C) 2020 Buchholz $\mathbf{N}$ et al. This is an open access peer review report distributed under the terms of the Creative Commons Attribution License, which permits unrestricted use, distribution, and reproduction in any medium, provided the original work is properly cited.

\section{Noor Buchholz}

U-merge Ltd. (Urology for Emerging Countries), London, UK

\section{Andreas Bourdoumis}

Pennine Acute Hospitals NHS Trust, Manchester, UK

The authors need to be congratulated for this effort. They produced a comprehensive review on supine versus prone position in PCNL. This former method has been around for now almost 15 years, and still surgeons remain unsure whether there is a benefit in adopting the supine position over the established and older prone position. In that sense, this article may be a good decision tool.

The authors systematically reviewed the relevant literature. The reviewer misses some evidence but the authors used stringent selection criteria which may have led to their exclusion but in turn make the data more robust. An example would be: 
Kachrilas S, Papatsoris A, Bach C, Kontos S, Faruquz Z, Goyal A, Masood J,BUCHHOLZ N. Colon perforation during percutaneous renal surgery: a 10-year experience in a single endourology centre. Urol Res. 2012 Jun;40(3):263-8¹.

This article shows on a large number of patients that there is no difference in complications in the right hands.

Although in most experienced hands, the differences between the two methods are minimal in all aspects, and the advantages of supine are evident to most surgeons who use it, somewhat surprisingly to me the analysed data show better safety in supine, and better stone-free rate in prone PCNL. Since there seems to be no flaw in their analysis, we will have to believe this data.

That makes it even more important to index.

\section{References}

1. Kachrilas S, Stefanos K, Papatsoris A, Athanasios P, et al.: Colon perforation during percutaneous renal surgery: a 10-year experience in a single endourology centre.Urol Res. 2012; 40 (3): 263-8 PubMed Abstract | Publisher Full Text

Are the rationale for, and objectives of, the Systematic Review clearly stated?

Yes

Are sufficient details of the methods and analysis provided to allow replication by others? Yes

Is the statistical analysis and its interpretation appropriate?

Yes

Are the conclusions drawn adequately supported by the results presented in the review? Yes

Competing Interests: No competing interests were disclosed.

Reviewer Expertise: Stone surgery, PCNL

We confirm that we have read this submission and believe that we have an appropriate level of expertise to confirm that it is of an acceptable scientific standard. 
The benefits of publishing with F1000Research:

- Your article is published within days, with no editorial bias

- You can publish traditional articles, null/negative results, case reports, data notes and more

- The peer review process is transparent and collaborative

- Your article is indexed in PubMed after passing peer review

- Dedicated customer support at every stage

For pre-submission enquiries, contact research@f1000.com 